\title{
Tricarboxylic Acid Cycle Activity in Relation to Itaconic Acid Biosynthesis ! by Aspergillus terreus
}

\author{
By N. WINSKILL $\dagger$ \\ Pfizer Central Research, Sandwich, Kent CT13 9NJ, U.K.
}

(Received 30 December 1982; revised 8 March 1983)

Cell-free extracts of an itaconic acid producing strain of Aspergillus terreus contained NADPdependent isocitrate dehydrogenase activity but no NAD-dependent activity was detected. During the acid-producing phase the activity of the NADP-linked enzyme fell to one-eighth of its value during the growth phase, whereas citrate synthase activity increased. Intact mitochondria were isolated from growth and production phase mycelium. The preparation from the growth phase oxidized exogenous NADH and all tricarboxylic acid cycle intermediates tested. That from the production phase oxidized tricarboxylic acid cycle intermediates at a reduced rate but exogenous NADH oxidation remained high. $\left[2{ }^{14} \mathrm{C}\right]$ Acetate was incorporated into itaconic acid and over $90 \%$ of the incorporated radioactivity was located in the methylene carbon. $[1-14 \mathrm{C}]-$ Acetate was a poorer precursor and did not preferentially label the methylene carbon. These results support the view that itaconic acid biosynthesis in $A$. terreus occurs by decarboxylation of aconitic acid, the latter produced by the normal reactions of the tricarboxylic acid cycle.

\section{INTRODUCTION}

Itaconic acid (methylene succinic acid) was first isolated as a fungal metabolite from Aspergillus itaconicus (Kinoshita, 1931) and was later shown to be produced by other fungi, notably Aspergillus terreus (Calam et al., 1939). Many workers have studied the biosynthesis of this relatively simple, commercially important compound and yet the problem is still not unequivocally resolved.

Bentley \& Thiessen $(1957 b, c)$ found evidence for the dissimilation of glucose by the EmbdenMeyerhof pathw and the tricarboxylic acid cycle and demonstrated the decarboxylation of cisaconitic acid to itâconic acid and $\mathrm{CO}_{2}$ by a crude enzyme preparation from $A$. terreus NRRL 1960. They concluded that cis-aconitic acid, produced by the normal reactions of the tricarboxylic acid cycle, was the immediate precursor of itaconic acid. The distribution of label following the incorporation of ${ }^{14} \mathrm{C}$-labelled glucose, acetate and succinate (Bentley \& Thiessen, $1957 a$ ) and the incorporation of labelled citrate (Corzo \& Tatum, 1953) provided further evidence for this route.

However, Nowakowska-Waszczuk (1973) found no evidence of active tricarboxylic acid cycle enzymes in A. terreus NRRL 1960 or two high yielding mutants derived from it. Mitochondria extracted from these strains oxidized reduced pyridine nucleotides with good respiratory control but were unable to oxidize tricarboxylic acid cycle intermediates either in the presence of ADP, cytochrome $c$ or after disruption of the mitochondrial membrane. She concluded that itaconic acid was not produced via the tricarboxylic acid cycle, thus supporting a view held by earlier workers (Shimi \& Nour El Dein, 1962; Lal \& Bhargava, 1962).

The aim of the work described here was to study tricarboxylic acid cycle activity in relation to itaconic acid synthesis by $A$. terreus M490, a high yielding strain used for the industrial production of itaconic acid.

$\dagger$ Present address: Pfizer International, 235 E 42nd St, New York, U.S.A. 


\section{METHODS}

Organism and culture methods. The strain used in this work was $A$. terreus $\mathbf{M} 490$. It was maintained on slants $\left(15 \mathrm{ml}\right.$ ) of the following composition: $\mathrm{NaCl}, 20 \mathrm{~g}$; glucose, $2.5 \mathrm{~g} ; \mathrm{KCl}, 0.5 \mathrm{~g} ; \mathrm{MgSO}_{4} .7 \mathrm{H}_{2} \mathrm{O}, 0.5 \mathrm{~g} ; \mathrm{FeSO}_{4}, 0.05 \mathrm{~g}$; Bacto-peptone (Difco), $2.5 \mathrm{~g}$; agar, $20 \mathrm{~g}$; made up to 1 litre with tap water and adjusted to $\mathrm{pH} 6.9$ to 7.0 with $\mathrm{KOH}$. Shake-flask fermentations were carried out in $50 \mathrm{ml}$ of a glucose/ammonia-based medium described by Nowakowska-Waszczuk (1973) in $300 \mathrm{ml}$ conical flasks. Each flask was inoculated with $1 \mathrm{ml}$ of a spore suspension obtained by suspending the spores from one slant in $10 \mathrm{ml}$ of water, and incubated on a rotary shaker at 300 r.p.m. at $30^{\circ} \mathrm{C}$.

Enzyme assays. Cells were harvested by filtration and washed with distilled water. All subsequent operations were carried out at $4{ }^{\circ} \mathrm{C}$.

(i) Isocitric dehydrogenase. Wet mycelium $(5 \mathrm{~g})$ was ground in a mortar and pestle with acid-washed sand and $10 \mathrm{ml} 0 \cdot 1 \mathrm{M}$-potassium phosphate buffer $(\mathrm{pH} \mathrm{7.2)} \mathrm{containing} 1 \mathrm{mm-EDTA}$. The resulting slurry was centrifuged for $15 \mathrm{~min}$ at $2000 \mathrm{~g}$ and the supernatant fluid used to measure isocitric dehydrogenase activity. The standard assay solution contained, in a final volume of $3 \mathrm{ml}, 0.67 \mathrm{M}$-potassium phosphate buffer (pH 7.2), 1.33 $\mathrm{nM}^{-\mathrm{MnSO}_{4}}$ (or $\mathrm{MgSO}_{4}$ ), 1.33 mM-sodium DL-isocitrate, 0.1 mM-NADP (or NAD), 0.67 mM-sodium EDTA (pH 7.2), $0.33 \%$ gelatin and $0.05 \mathrm{ml}$ enzyme solution. The increase in absorbance at $340 \mathrm{~nm}$ was followed at $30 \mathrm{~s}$ intervals over a $4 \mathrm{~min}$ period at $25^{\circ} \mathrm{C}$ in a $1 \mathrm{~cm}$ light-path cuvette. A blank solution containing all of the above reagents except isocitrate was included with each assay. NAD-linked activity was also measured in the presence of $0 \cdot 5 \mathrm{mM}-\mathrm{AMP}$.

(ii) Citrate synthase. Wet mycelium ( $4 \mathrm{~g}$ ) was ground with acid-washed sand and $15 \mathrm{ml} 1 \mathrm{M}$-Tris buffer ( $\mathrm{pH} 8 \cdot 1)$ in a mortar and pestle. The resulting slurry was centrifuged at $2000 \mathrm{~g}$ for $15 \mathrm{~min}$ and the supernatant fluid used for the assay of citrate synthase activity. This was measured by the spectrophotometric method of Srere (1969) using 5,5'-dithiobis(2-nitrobenzoate) (DTNB) to measure the release of free coenzyme A from acetyl CoA on the addition of oxaloacetate.

Preparation of mitochondrial pellet. Cells were harvested by filtration through a Buchner funnel and washed with distilled water and then ice-cold $0.7 \mathrm{M}$-mannitol solution. All subsequent procedures were carried out at $4{ }^{\circ} \mathrm{C}$. Wet cells ( $2 \mathrm{~g}$ ) were ground for $4 \mathrm{~min}$ in a ground-glass mortar and pestle with $3 \mathrm{~g}$ of acid-washed sand and $2 \mathrm{ml}$ of a medium containing $0.5 \mathrm{M}$-mannitol, $4 \mathrm{mM}$-sodium EDTA and $10 \mathrm{mM}$-potassium phosphate buffer (pH 7.0) (medium A). The resulting paste was suspended in a further $50 \mathrm{ml}$ of medium A and centrifuged for $10 \mathrm{~min}$ at $1000 \mathrm{~g}$. The supernatant fluid was decanted and centrifuged at $12000 \mathrm{~g}$ for $15 \mathrm{~min}$. The resulting mitochondrial pellet was resuspended in $20 \mathrm{ml}$ of medium $\mathrm{A}$ and the above centrifugation procedure repeated. The final pellet was resuspended in $2 \mathrm{ml}$ of a medium containing $0.5 \mathrm{M}$-mannitol, $0.4 \mathrm{~mm}$-sodium EDTA, $10 \mathrm{~mm}$-potassium phosphate buffer ( $\mathrm{pH} \mathrm{7.2)} \mathrm{and} 0.2 \%$ bovine serum albumin (medium B). This suspension was used to measure mitochondrial activity.

Measurement of oxygen uptake. Respiratory activity of mitochondrial fractions was measured at $30^{\circ} \mathrm{C}$ with an oxygen electrode (Rank Brothers, Bottisham, Cambridge, U.K.) as described in the legend to Table 3. Nucleotides and tricarboxylic acid cycle intermediates were purchased from Sigma.

Analyses. Growth was estimated by centrifuging a sample of culture broth in a graduated centrifuge tube at 2000 r.p.m. for $5 \mathrm{~min}$ and measuring the volume of the mycelial pellet. Glucose was determined by an automated neocuproine method (Bittner \& Manning, 1967). Itaconic acid was assayed by bromination (Friedkin, 1945). Protein was measured by the biuret reaction after solubilization with hot $\mathrm{NaOH}$ (Stickland, 1951).

Incorporation of acetate. Sodium $\left[1{ }^{14} \mathrm{C}\right]$ acetate $\left[6.07 \mu \mathrm{Ci} ; 59 \cdot 1 \mathrm{mCi} \mathrm{mmol}^{-1}\left(2 \cdot 187 \mathrm{GBq} \mathrm{mmol}{ }^{-1}\right)\right]$ or sodium $\left[2-{ }^{14} \mathrm{C}\right]$ acetate $\left[6 \cdot 12 \mu \mathrm{Ci} ; 59 \cdot 1 \mathrm{mCi} \mathrm{mmol}^{-1}\left(2 \cdot 187 \mathrm{GBq}^{\mathrm{mmol}}{ }^{-1}\right)\right]$ (both from Amersham) were separately added in $1 \mathrm{ml}$ of water, to two 64 -h-old shake flask fermentations and incubated for a further $4 \mathrm{~h}$. The duplicate flasks were combined, filtered and the itaconic acid content of the culture filtrate determined. A $10 \mathrm{ml}$ volume of culture filtrate was extracted with butanol $(3 \times 10 \mathrm{ml})$. The butanol was evaporated under vacuum and the itaconic acid in the residue purified and recovered by preparative TLC on silica gel plates (Merck) using a solvent system composed of diethyl ether/acetic acid $(14: 1, \mathrm{v} / \mathrm{v})$. The radiochemical content of the purified itaconic acid was measured by liquid scintillation counting.

Degradation of itaconic acid. Itaconic acid was degraded by reductive ozonolysis and the formaldehyde so formed from the methylene carbon was converted to its 2,4-dinitrophenylhydrazone (Corzo, 1953) and recrystallized to constant specific activity from methanol $/ \mathrm{H}_{2} \mathrm{O}$.

Measurement of radioactivity. Radioactivity was measured by dissolving the substrate in the minimum amount of water or methanol, adding to $10 \mathrm{ml}$ of Instagel (Packard) and counting in a liquid scintillation counter (Nuclear Chicago Mark III).

\section{RESULTS}

The data in Fig. 1 show a typical time course of glucose utilization, biomass accumulation and itaconic acid production by $A$. terreus M490 under the shake-flask conditions used throughout 


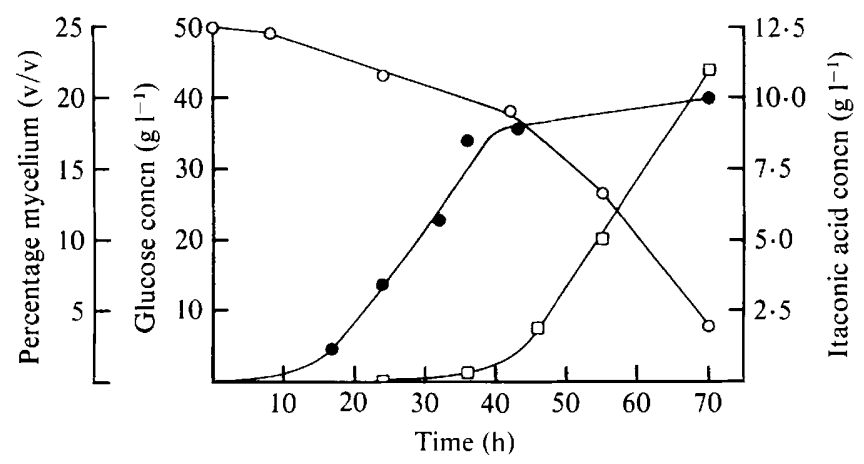

Fig. 1. Time course of glucose utilization, growth and itaconic acid production by $A$. terreus. Flasks containing a medium with glucose as carbon source and $\mathrm{NH}_{4}^{+}$as nitrogen source were inoculated with a spore suspension and incubated on a shaker at 300 r.p.m. at $30^{\circ} \mathrm{C}$. Glucose utilization $(O)$, mycelium concentration ( $)$ and itaconic acid concentration ( $\square$ ) were measured as described in Methods.

this work. The fermentation can be conveniently divided into a growth phase, during which no significant itaconic acid synthesis occurs, and an acid-producing phase during which the linear rate of growth decreases, or stops altogether, and itaconic acid is accumulated.

\section{Isocitrate dehydrogenase and citrate synthase}

Two of the key enzymes involved in the tricarboxylic acid cycle scheme of itaconic acid biosynthesis are citrate synthase and isocitrate dehydrogenase. Citrate synthase activity should remain high during both the growth and production phase whereas isocitric dehydrogenase(s) may be active during the growth phase to allow for efficient cell synthesis but should be low during the acid-producing phase to maximize the flow of carbon substrate towards itaconic acid production. Therefore, the activity of these two enzymes was studied in crude cell-free extracts.

NADP-linked isocitrate dehydrogenase (EC 1.1.1.42) activity was readily detectable in $A$. terreus M490. The enzyme showed a requirement for $\mathrm{Mn}^{2+}$ or $\mathrm{Mg}^{2+}, \mathrm{Mn}^{2+}$ being the better cofactor. No NAD-linked activity (EC 1.1.1.41) was found, with or without exogenous AMP $(0.5 \mathrm{mM})$, although the presence of an unstable enzyme cannot be ruled out. By comparison, Aspergillus nidulans contains only an NADP-dependent dehydrogenase (Hankinson \& Cove, 1974) whereas both enzymes are present in Aspergillus niger (Ramakrishnan \& Martin, 1955) and other fungi (Kornberg \& Pricer, 1951; Sanwal \& Slachow, 1965). The NADP-dependent enzyme of $A$. niger also requires either $\mathrm{Mn}^{2+}$ or $\mathrm{Mg}^{2+}$, but only $\mathrm{Mg}^{2+}$ activates the NAD-linked enzyme (Ramakrishnan \& Martin, 1955).

The addition of itaconic acid to the assay medium at concentrations up to $4 \mathrm{~mm}$ caused no inhibition of NADP-dependent isocitric dehydrogenase activity.

Citrate synthase (EC 4.1.3.7) activity was found to be present during both phases of the fermentation and was actually higher during the production phase. In contrast, the activity of the NADP-linked isocitrate dehydrogenase was high during the growth phase but fell to oneeighth of this value during the production phase (Table 1).

\section{Respiratory activity of mitochondria extracted from growth and production phase mycelium}

Mitochondria isolated from $A$. terreus M490 oxidized all exogenous tricarboxylic acid cycle intermediates tested, as well as NADH (Table 2). The respiratory control ratios were rather low, reflecting the difficulty of isolating intact mitochondria from this strain, but were sufficient to measure ADP :O ratios and the observed values were analogous to those reported for $A$. niger (Watson \& Smith, 1967) and Aspergillus oryzae (Watson et al., 1969).

The most obvious difference between the mitochondria extracted from the two different phases of the fermentation was that the preparation from the acid-producing phase oxidized tricarboxylic acid cycle intermediates at a significantly reduced rate, although exogenous $\mathrm{NADH}$ oxidation was more rapid. The rate of pyruvate plus malate oxidation was reduced less 
Table 1. Specific activity of citrate synthase and NADP-dependent isocitrate dehydrogenase in cell-free extracts of growth and production phase mycelium of $A$. terreus

Cells were harvested from different phases of an $A$. terreus shake-flask fermentation. Citrate synthase activity was measured as described in Methods. One unit of enzyme activity is defined as that amount which liberates $1 \mu \mathrm{mol}$ coenzyme $\mathrm{A} \mathrm{min}{ }^{-1}$ under the stated assay conditions. Specific activity is expressed as units (mg protein) ${ }^{-1}$. NADP-dependent isocitric dehydrogenase activity was measured as described in Methods, with $\mathrm{Mn}^{2+}$ as activator. One unit of enzyme activity is defined as that which causes an increase in absorbance of $0.01 \mathrm{~min}^{-1}$ under the stated conditions.

\begin{tabular}{lcc} 
Phase & \multicolumn{2}{c}{$\begin{array}{c}\text { NADP-dependent isocitric } \\
\text { dehydrogenase }\end{array}$} \\
Growth phase $(26 \mathrm{~h})$ & 2.51 & $23 \cdot 1$ \\
Production phase $(62 \mathrm{~h})$ & 4.72 & 2.9
\end{tabular}

Table 2. Respiratory activity of A. terreus mitochondria isolated from growth and production phase cells

The reaction mixture contained, in a final volume of $2 \mathrm{ml}$ of medium B (see Methods), mitochondrial protein, $1.45 \mathrm{mg}$ (growth phase preparation) or $2.97 \mathrm{mg}$ (production phase preparation). The concentration of substrates was $6 \mathrm{mM}$ except for NADH (1 mM). Respiratory control (RC) and ADP :O ratios were measured by the method of Chance \& Williams (1956) after adding ADP to a concentration of $0.05 \mathrm{mM}$. Oxygen uptake is expressed at State 3 (in the presence of ADP).

\begin{tabular}{|c|c|c|c|c|c|c|}
\hline \multirow[b]{2}{*}{ Substrate } & \multicolumn{3}{|c|}{$\begin{array}{c}\text { Growth phase } \\
(19 \mathrm{~h})\end{array}$} & \multicolumn{3}{|c|}{$\begin{array}{c}\text { Production phase } \\
(67 \mathrm{~h})\end{array}$} \\
\hline & $\begin{array}{l}\text { Oxygen uptake } \\
\text { [ng-atom } \text { min }^{-1} \\
(\mathrm{mg} \text { protein })^{-1} \text { ] }\end{array}$ & $\begin{array}{c}\mathrm{RC} \\
\text { ratio }\end{array}$ & $\begin{array}{c}\text { ADP : } \mathrm{O} \\
\text { ratio }\end{array}$ & $\begin{array}{l}\text { Oxygen uptake } \\
\text { [ng-atom min }{ }^{-1} \\
\left.(\mathrm{mg} \text { protein })^{-1}\right]\end{array}$ & $\begin{array}{c}\mathrm{RC} \\
\text { ratio }\end{array}$ & $\begin{array}{c}\text { ADP : } O \\
\text { ratio }\end{array}$ \\
\hline NADH & $51 \cdot 4$ & $1 \cdot 3$ & $1 \cdot 3$ & $81 \cdot 7$ & $1 \cdot 3$ & $1 \cdot 3$ \\
\hline Pyruvate + malate & $30 \cdot 2$ & $1 \cdot 2$ & $1 \cdot 8$ & $16 \cdot 7$ & 1.4 & $1 \cdot 7$ \\
\hline Succinate & $48 \cdot 0$ & 1.4 & $1 \cdot 4$ & $9 \cdot 4$ & $1 \cdot 4$ & $1 \cdot 3$ \\
\hline$\alpha$-Oxoglutarate & $30 \cdot 2$ & $1 \cdot 2$ & $1 \cdot 9$ & $2 \cdot 7$ & $2 \cdot 0$ & 1.9 \\
\hline Citrate & $17 \cdot 8$ & $2 \cdot 1$ & $2 \cdot 1$ & $4 \cdot 0$ & $3 \cdot 0$ & 1.9 \\
\hline
\end{tabular}

than that of the other acids tested. Pyruvate plus malate oxidation is an indicator of citrate synthase activity but the two are not directly proportional since the activity of the post-citrate dehydrogenase also affects this oxidation rate. If the rate of citrate oxidation is subtracted from the rate of pyruvate plus malate oxidation in order to estimate citrate synthase activity, assuming that formation of acetyl $\mathrm{CoA}$ and oxaloacetate from pyruvate and malate are not rate limiting, then this was as high during the production phase as during the growth phase. Thus the activity found in mitochondria was consistent with that found in cell-free extracts by the more direct assay procedures. Furthermore, the changes in activity were very similar to those observed in mitochondria isolated from growth and production phase cells of a high yielding citric acid strain of Candida lipolytica which is thought to produce citric acid via the tricarboxylic acid cycle (Mitsushima et al., 1976).

\section{Incorporation of $\left[1-{ }^{14} \mathrm{C}\right]$ acetate and $\left[2-{ }^{14} \mathrm{C}\right]$ acetate}

It has been proposed that itaconate biosynthesis might involve condensation of pyruvate and acetyl coenzyme A to form citramalic acid followed by dehydration to itaconic acid (Smith et al., 1974; Jakubowska, 1977). According to this scheme, both carbon atoms of labelled acetate should be incorporated into itaconic acid and should label the C-1 and C-2 atoms. On the other hand, because of the asymmetric nature of citrate to the aconitase enzyme and the stereochemistry of the cis-aconitic decarboxylase (EC 4.1.1.6) of A. terreus (Bentley \& Thiessen, $1957 c$ ), the tricarboxylic acid cycle route predicts that only C-2 of acetate should be incorporated and that this should label the C-5 atom of itaconic acid (Fig. 2). Thus the incorporation of 
(a) Via the tricarboxylic acid cycle

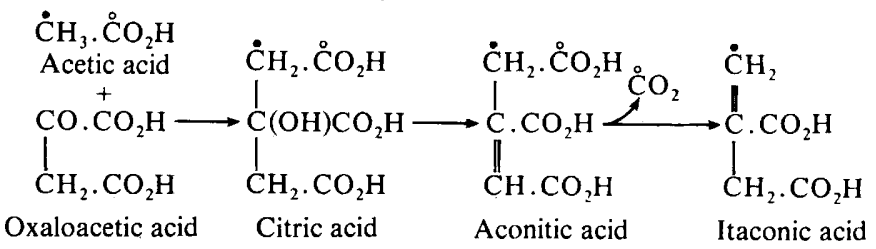

(b) Via citramalic acid

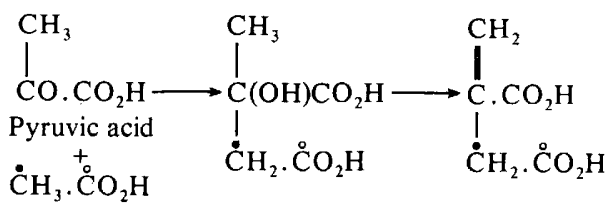

Fig. 2. Theoretical labelling of itaconic acid from acetate. The open circles and filled circles show the expected labelling from $\left[1-1^{4} \mathrm{C}\right]$ acetate and $\left[2-1^{4} \mathrm{C}\right] \mathrm{acetate}$, respectively.

\section{Table 3. Incorporation of acetate into itaconic acid}

Each precursor was added separately to two 64-h-old shake-flask fermentations. After a further $4 \mathrm{~h}$ incubation the duplicate flasks were pooled, filtered and the itaconic acid content of the filtrate determined. The itaconic acid was extracted into butanol, purified by preparative TLC and counted by liquid scintillation counting. A further portion was degraded by reductive ozonolysis and the formaldehyde so formed from the C-5 (methylene) atom of itaconic acid was converted to its 2,4dinitrophenylhydrazone and recrystallized to constant specific activity in order to determine the percentage of the incorporated activity located at C-5.

\begin{tabular}{|c|c|c|c|c|c|c|c|}
\hline & \multicolumn{2}{|c|}{ Precursor } & \multicolumn{5}{|c|}{ Itaconic acid } \\
\hline & $\begin{array}{l}\text { Amount } \\
\text { added } \\
(\mu \mathrm{Ci})\end{array}$ & $\begin{array}{c}\text { Specific } \\
\text { activity } \\
(\mathrm{mCi} \\
\left.\mathrm{mmol}^{-1}\right)\end{array}$ & $\begin{array}{l}\text { Amount } \\
\text { produced } \\
(\mathrm{mg})\end{array}$ & $\begin{array}{c}\text { Total } \\
\text { activity } \\
(\mu \mathrm{Ci})\end{array}$ & $\begin{array}{l}\text { Specific } \\
\text { activity } \\
(\mu \mathrm{Ci} \\
\left.\mathrm{mmol}^{-1}\right)\end{array}$ & $\begin{array}{l}\text { Percentage } \\
\text { incor- } \\
\text { poration }\end{array}$ & $\begin{array}{c}\text { Percentage } \\
\text { of }{ }^{1+} \mathrm{C} \\
\text { located } \\
\text { at } \mathrm{C}-5\end{array}$ \\
\hline$[1-1+C]$ Acetate & $12 \cdot 14$ & $59 \cdot 1$ & 848 & $2 \cdot 13$ & 0.33 & $17 \cdot 5$ & $13 \cdot 4$ \\
\hline$\left[2^{-1+}\right.$ C]Acetate & $12 \cdot 24$ & $59 \cdot 1$ & 773 & 4.85 & 0.82 & $39 \cdot 7$ & $90 \cdot 3$ \\
\hline
\end{tabular}

$\left[1-{ }^{14} \mathrm{C}\right]$ acetate and $\left[2-{ }^{14} \mathrm{C}\right]$ acetate can be used to differentiate between these two alternative schemes.

When $\left[1-{ }^{14} \mathrm{C}\right]$ acetate and $\left[2-{ }^{14} \mathrm{C}\right]$ acetate were added separately to $A$. terreus $\mathrm{M} 490$ shake-flask fermentations and the itaconic acid was assayed $4 \mathrm{~h}$ later it was found that $\left[2-{ }^{14} \mathrm{C}\right]$ acetate was a much better precursor than $\left[1-{ }^{14} \mathrm{C}\right]$ acetate. Furthermore, over $90 \%$ of the label incorporated from $\left[2{ }^{14} \mathrm{C}\right]$ acetate was located at C-5 whereas only $13 \%$ of the label from $\left[1-{ }^{14} \mathrm{C}\right]$ acetate was located at this position (Table 3 ).

\section{DISCUSSION}

The fact that fermentation conditions required to achieve high yields of itaconic acid from $A$. terreus are in many ways similar to those required for good yields of citric acid from $A$. niger (Miall, 1978) suggests certain common regulatory mechanisms. The production of both acids can be considered as arising from disruption of the normal reactions of the tricarboxylic acid cycle, but this is not universally accepted.

Ramakrishnan et al. (1955) proposed that the loss of aconitase and isocitrate dehydrogenase activity during the later stages of the growth of $A$. niger offered an explanation of citric acid accumulation by this fungus. La Nauze (1966) reported that all enzymes of the tricarboxylic acid cycle were active during citric acid production and argued that citric acid did not, therefore, 
accumulate because of a blockage at aconitase or isocitrate dehydrogenase. This contradiction may have been resolved by Mattey (1977) who showed that the NADP-dependent isocitrate dehydrogenase of $A$. niger was inhibited by concentrations of citrate within the normal physiological range in the mycelium so that citrate itself may at least in part regulate its own overproduction via the tricarboxylic acid cycle by inhibiting this enzyme. In yeasts, citrate accumulation might be controlled by energy charge regulation of the NAD-dependent isocitrate dehydrogenase (Mitsushima et al., 1978).

In contrast to earlier work (Nowakowska-Waszczuk, 1973), the results reported here demonstrate that $A$. terreus contains some of the key enzymes necessary for itaconic acid production via the tricarboxylic acid cycle. The reason for this apparent contradiction in results is unknown but is possibly related to the difficulty of isolating active mitochondria from fungal sources: Nowakowska-Waszczuk only looked for activity in mitochondrial preparations. Initial attempts to extract intact mitochondria from A. terreus M490 in our own laboratory were unsuccessful. In some cases, mitochondrial preparations were obtained which oxidized exogenous NADH but not organic acids, as was found by Nowakowska-Waszczuk, although her preparations showed respiratory control while ours did not. However, the isolation procedure described in Methods has, on a large number of occasions, consistently given preparations which oxidize tricarboxylic cycle intermediates. It would be interesting to know whether similar activity can be found in the strains used by Nowakowska-Waszczuk using more direct enzyme assays which do not necessitate the extraction of intact mitochondria.

In the shake-flask system employed in the present study, most of the carbon from the substrate not incorporated into cells and itaconic acid is liberated as $\mathrm{CO}_{2}$. Complete oxidation of substrate in the tricarboxylic acid cycle could account for this as the isocitric dehydrogenase is only partially blocked during the production phase. Commercial fermentation conditions give much higher yields of itaconic acid with consequently less loss of carbon as $\mathrm{CO}_{2}$. In cell-free extracts of strain M490 isolated from such fermentations, citrate synthase activity was again higher during the production phase but NADP-dependent isocitrate dehydrogenase activity fell to less than $1 / 40$ of its value during the growth phase, compared to the eightfold drop in shakeflasks (Table 1), whereas other measured tricarboxylic acid cycle enzymes were less severely restricted (N. Winskill, unpublished results). Thus the regulation of isocitrate dehydrogenase activity appears to be a critical factor in itaconic acid overproduction, as in the production of citric acid.

Itaconic acid does not seem to inhibit the isocitrate dehydrogenase of $A$. terreus, and as this enzyme does not require AMP for activation it is unlikely to be controlled by the energy charge of the cell. It is well known that reducing the concentration of certain metals in the medium increases itaconic acid yields (see references in Miall, 1978). One effect of this might be to remove the $\mathrm{Mn}^{2+}$ required for maximum isocitrate dehydrogenase activity. However, fermentation media usually contain excess $\mathrm{Mg}^{2+}$, an alternative activator, and assuming this is available other regulatory mechanisms must apply.

The incorporation of $\left[2-{ }^{14} \mathrm{C}\right]$ acetate into itaconic acid and the preferential labelling of the C-5 carbon atom from this precursor is consistent with the tricarboxylic acid cycle scheme of itaconic acid biosynthesis. In a similar experiment with strain NRRL 1960, Corzo (1953) and Corzo \& Tatum (1953) obtained analogous results but found a somewhat lower degree of localization of label at C-5 $(60 \%)$, probably because of the longer incubation periods employed in their study.

Some degree of incorporation of $\left[1-{ }^{14} \mathrm{C}\right]$ acetate is predicted according to this route because the C-1 atom of acetate, initially incorporated into citric acid, is lost as $\mathrm{CO}_{2}$. Fixation of this $\mathrm{CO}_{2}$ by the Wood-Werkman reaction and subsequent conversion of the so-labelled oxaloacetate to itaconic acid would result in label in the carboxyl carbons of itaconate. Bentley \& Thiessen $(1957 a)$ did in fact show that almost all of the ${ }^{14} \mathrm{C}$ from $\left[1-{ }^{14} \mathrm{C}\right]$ acetate incorporation was located equally in the carboxyl groups of itaconic acid. Although the simple degradation scheme employed in the present study did not differentiate between labelling of the C-1, C-2, C-3 and $\mathrm{C}-4$ atoms, the low degree of localization of label from $\left[1^{-14} \mathrm{C}\right]$ acetate at the $\mathrm{C}-5$ position agrees with their findings. 
These results are inconsistent with a route to itaconic acid from acetate and pyruvate via citramalic acid, and insofar as the tricarboxylic acid cycle scheme explains these and most other experimental observations it would appear that $A$. terreus produces itaconic acid by the latter mechanism.

I would like to thank Mr M. E. J. East for capable technical assistance and Mr L. M. Miall and Drs K. S. Holdom and P. M. Rhodes for helpful discussion and advice.

\section{REFERENCES}

Bentley, R. \& ThIESSEN, C. P. (1957a). Biosynthesis of itaconic acid in Aspergillus terreus. I. Tracer studies with $\mathrm{C}^{14}$-labelled substrates. Journal of Biological Chemistry 226, 673-687.

Bentley, R. \& Thiessen, C. P. (1957b). Biosynthesis of itaconic acid in Aspergillus terreus. II. Early stages in glucose dissimilation and the role of citrate. Journal of Biological Chemistry 226, 689-701.

Bentley, R. \& Thiessen, C. P. (1957c). Biosynthesis of itaconic acid in Aspergillus terreus. III. The properties and reaction mechanism of $c i s$-aconitic decarboxylase. Journal of Biological Chemistry 226, 703720.

BitTner, D. L. \& MANning, J. (1967). Automated neocuproine glucose method: critical factors and normal values. In Automation in Analytical Chemistry, Technicon Symposia, 1966, vol. 1, pp. 33-36. White Plains, New York: Mediad.

CALAM, C. T., OXford, A. E. \& RAistrick, H. (1939). The biochemistry of microorganisms. LXIII. Itaconic acid a metabolic product of a strain of Aspergillus terreus Thom. Biochemical Journal 33, 1488-1495.

Chance, B. \& Williams, G. R. (1956). The respiratory chain and oxidative phosphorylation. Advances in Enzymology 17, 65-134.

CoRzo, R. H. (1953). Biosynthesis of itaconic acid by Aspergillus terreus. Ph.D. thesis, Stanford University, U.S.A.

Corzo, R. H. \& TATUM, E. L. (1953). Biosynthesis of itaconic acid. Federation Proceedings 12, 470.

FrIEDKIN, M. (1945). Determination of itaconic acid in fermentation liquors. Industrial and Engineering Chemistry. Analytical Edition 17, 637-638.

Hankinson, O. \& Cove, D. J. (1974). Regulation of the pentose phosphate pathway in the fungus Aspergillus nidulans. Journal of Biological Chemistry 249, 23442353.

JAKUBOWSKA, J. (1977). Itaconic and itatartaric acid biosynthesis. In Genetics and Physiology of Aspergillus, British Mycological Society Symposium, Series no. 1, pp. 427-451. Edited by J. E. Smith \& J. A. Pateman. London: Academic Press.

Kinoshita, K. (1931). Uber eine neue Aspergillus Art, A. itaconicus. Botanical Magazine (Tokyo) 45, 45-61.

Kornberg, A. \& Pricer, W. E. (1951). Di- and triphosphopyridine nucleotide isocitrate dehydrogenase in yeast. Journal of Biological Chemistry 189, 123-136.

LAL, M. \& BhaRgava, P. M. (1962). Reversal by pyruvate of fluoride inhibition in Aspergillus terreus. Biochimica et biophysica acta 58, 628-630.

LA Nauze, J. M. (1966). Aconitase and isocitric dehydrogenase of Aspergillus niger in relation to citric acid production. Journal of General Microbiology 44, 73-81.

MATTEY, M. (1977). Citrate regulation of citric acid production in Aspergillus niger. FEMS Microbiology Letters 2, 71-74.

Miall, L. M. (1978). Organic acids. In Primary Products of Metabolism, pp. 47-119. Edited by A. H. Rose. London: Academic Press.

Mitsushima, K., Shinmyo, A. \& Enatsu, U. (1976). Respiration activity in mitochondria prepared from cells of Candida lipolytica at different growth phases. Journal of Fermentation Technology 54, 863-871.

Mirsushima, K., Shinmyo, A. \& Enatsu, U. (1978). Control of citrate and 2-oxoglutarate formation in Candida lipolytica by adenine nucleotides. Biochimica et biophysica acta 538, 481-492.

NowaKowSKA-WASzczUCK, A. (1973). Utilization of some tricarboxylic acid cycle intermediates by mitochondria and growing mycelium of Aspergillus terreus. Journal of General Microbiology 79, 19-29.

RamakrishnaN, C. V. \& MARTIN, S. M. (1955). Isocitrate dehydrogenase in Aspergillus niger. Archives of Biochemistry and Biophysics 55, 403-407.

Ramakrishnan, C. V., Steel, R. \& Lentz, C. P. (1955). Mechanisms of citric acid formation and accumulation in Aspergillus niger. Archives of Biochemistry and Biophysics 55, 270-273.

Sanwal, B. D. \& Slachow, C. S. (1965). Allosteric activation of nicotinamide adenine dinucleotide specific isocitrate dehydrogenase of Neurospora. Biochimica et biophysica acta 96, 28-44.

Shimi, I. R. \& Nour El DeIN, M. S. (1962). Biosynthesis of itaconic acid by Aspergillus terreus. Archiv für Mikrobiologie 44, 181-188.

Smith, J. E., NowakowsKa-WaszczuK, A. \& ANDERSON, J. G. (1974). Organic acid production by mycelial fungi. In Industrial Aspects of Biochemistry, vol. 1, pp. 297-317. Edited by B. Spencer. Amsterdam: Elsevier.

Srere, P. A. (1969). Citrate synthase. Methods in Enzymology 13, 4-5.

Stickland, L. H. (1951). The determination of small quantities of bacteria by means of the biuret reaction. Journal of General Microbiology 5, 698-703.

Watson, K. \& SMITH, J. E. (1967). Oxidative phosphorylation and respiratory control in mitochondria from Aspergillus niger. Biochemical Journal 104, 332339.

Watson, K., Paton, W. \& Smith, J. E. (1969). Oxidative phosphorylation and respiratory control in mitochondria from Aspergillus oryzae. Canadian Journal of Microbiology 15, 975-977. 